\title{
Food-Drug Interaction in Older Adults
}

\author{
Björn Viðar Aðalbjörnsson and Alfons Ramel
}

\begin{abstract}
The focus of this chapter is on food-drug interaction in older adults. We will discuss how foods can affect drug metabolism and also vice versa how drugs can affect dietary intake and nutrition status.
\end{abstract}

\section{Keywords}

Old people $\cdot$ Food-drug interaction $\cdot$ Herb-drug interaction $\cdot$ Nutrition status

\section{Learning Outcomes}

By the end of this chapter, you will be able to:

- Understand the importance of food-drug interactions.

- Know where the interactions take place.

- Describe common foods and herbal products which can affect drug metabolism.

- Report consequences of certain medications on nutrition status.

This chapter is a component of Part II: Specialist Versus Generalist Nutritional Care in Aging. For an explanation of the grouping of chapters in this book, please see Chap. 1: 'Overview of Nutrition Care in Geriatrics and Orthogeriatrics'.

B. V. Aðalbjörnsson $(\triangle) \cdot$ A. Ramel

Department of Food Science and Nutrition, School of Health, University of Iceland,

Reykjavík, Iceland

e-mail: bva@hi.is; alfonsra@hi.is

Ó. G. Geirsdóttir, J. J. Bell (eds.), Interdisciplinary Nutritional Management and 


\subsection{Introduction}

Medical drugs, or medicines, are used to treat diseases, and to guarantee their safety and efficacy, they must be applied in the appropriate way. Medicines usually contain active ingredients which react with the human metabolism in various ways, and certain dietary components frequently affect these properties of medicines. These so-called food-drug interactions occur when, for example, a dietary substance or food enhances, decreases or changes the activity of a drug. Further, a drug interaction can result into a new drug effect which would not occur on its own. Typically, such interactions can be observed between drugs and foods (food-drug interactions) but also between drugs and herbs (herb-drug interactions) [1].

Food-drug interactions can be observed as a consequence of accidental misuse or insufficient knowledge on the substances involved in the interaction. In many cases, herbs, fruits as well as alcohol can alter the efficacy of a given drug intervention with adverse consequences. In most cases, relevant food-drug interactions change the bioavailability of a medicine [1].

Less frequently discussed, but equally important, is the fact that interactions can also go the other way around, i.e. medical drugs can also affect nutrition. As medicines and nutrients employ often the same mechanisms for absorption and are metabolically converted and excreted via the same ways, regular use of certain medications has the potential to negatively influence nutritional status [1,2].

\subsection{Food and Herbal Product Interaction with Drugs}

Drug-drug interactions are well known, and particular attention is given to detailing these interactions, for example, on drug instructions or clinical databases and guides. Whilst traditionally there has been less discussion about food-drug interactions, this has been growing in the recent decade. This is an important area as oral drug dosing is common. Food-drug interactions may arise due to changes in drug kinetics, intestinal transport, metabolism and distribution. The effect of standard meals on the drug intake is tested during clinical trials, and recommendations are given based on these studies. Research has tried to quantify this effect, but once in clinical setting, the food intake can vary. Several reviews have discussed this issue with focus on older adults [3-8].

The food-drug interaction is a complex subject, and the interaction can be within the digestive system (e.g. uptake hindrance or binding to drug) or metabolic inhibition (e.g. liver enzymes) $[9,10]$. There are several factors that play part in these interactions. The condition of the patient is important, such as age, pre-existing conditions, organ malfunction and polypharmacy. The condition of the food and herbal products influences the composition, identity, extraction, processing, cooking and storage. This then interacts with drugs differently depending on their absorption, distribution, metabolism and distribution.

Food intake varies between age groups, cultures, socio-economic settings and institutions. A broad variety of common food products and herbal products have 
shown to have adverse effects [11, 12]. These can come from excessive consumption of common food items like fruits and vegetables [13]. Supplements are often concentrated components of food items, such as garlic oil, or herbal products. Both food and herbal supplements, even when taken in highly concentrated forms, are often considered safe by patients. The regulation landscape around supplements is different than for food and medical drugs and is complex and not uniform worldwide which can confuse consumers [14]. The use of supplements is common, and with increased awareness, attention and marketing regarding real or perceived health benefits, this may continue to increase in the coming years. However, in their review, Boullata and Hudson (2012) showed that $12-45 \%$ of people used both drugs and supplements, where 6-29\% were at risk of harmful interactions [7]. In another study including 1795 patients, 40\% reported the use of supplements [15]. Whilst garlic, valerian, kava, ginkgo and St John's wort contributed to more than two-thirds of potentially clinically significant interactions, 107 natural products with potential for interactions were identified. The risk of interactions was with common drug categories (antithrombotic, antidepressants and antidiabetics and sedatives).

A further difficulty is that patients that resort to herbal medications can do so without the knowledge of their medical professional or hide it as they feel ashamed, desperate or rebellious. Patients may also not report supplements or the use of herbal product as the public assumption is that they are safe (e.g. the common use of Ginkgo biloba, garlic, ginseng, St John's wort, Echinacea, saw palmetto, evening primrose and ginger). Bioavailability is not always negatively affected as iron supplementation can increase the bioavailability of tetracycline [16]. It is therefore important that there are an open dialogue and understanding between healthcare providers and patients.

As this is a complex subject, below are provided some case examples of common food and herbal product interactions with drugs.

\subsubsection{Common Foods}

Milk can reduce the bioavailability of drugs such as antibiotics (e.g. tetracycline, doxycycline and penicillin). A small amount of milk, such as in tea or coffee, has shown up to $49 \%$ reduction in tetracycline bioavailability [17]. Tetracycline and doxycycline are not solely affected by milk as food products can reduce the bioavailability significantly $[18,19]$. These effects are often known by health professional, but with these commonly used products, patients may fail to understand the extent of effect the food can have on drug efficacy. For example, a morning dose before breakfast may be difficult for those patients with the habit of starting the day with a meal and supplements. If the patient takes their medication afterwards, it is likely to lead to an unwanted effect (such as slower recovery). Provision of instructions for patients that are clear and outline the potential consequences may improve adherence to prescriptive instructions and, ultimately, patient outcomes.

Other popular common food products include grapefruit and cranberry juice. The interaction between grapefruit juice and drugs has been known for decades, but in the 
recent years, the number of reported cases has increased [20]. The effect of grape juice on cyclosporin includes decreased area-under-curve (30\%) and increased clearance (50\%) [21]. Other fruit juices can affect drug potency as well, both increasing and decreasing bioavailability [22]. Cranberry juice is frequently recommended for $\mathrm{H}$. pylori and urinary tract infections. Care must be taken though cranberry juice is considered safe and administered in high doses. Griffiths et al. reported in 2008 a fatal case of haemopericardium and gastrointestinal haemorrhage where interaction between grapefruit juice and enzymes is responsible for warfarin clearance [23]. In this case, the patient was on a recommended 300-400 mL of cranberry juice per day, 6 weeks prior to the incident.

Garlic is traditionally used as a common food across many cultures but is also increasingly (self) prescribed as an alternative natural medicine supplement.

Garlic has been studied extensively with regard to its chemistry, pharmacology and clinical properties. The main research interests lie in the area of anticancer, antimicrobial and cardiovascular effects [24, 25]. The sulphur-containing compounds within garlic are considered responsible for the varied bioactive effects. Allicin is a precursor to several of these compounds; it is broken down enzymatically by allinase that is activated when garlic tissue is disrupted, cut or mashed. These unstable compounds are mostly found in fresh or freeze-dried garlic products. These compounds can cause an inhibition of CYP450 3A4 substrates—such as statin medications (e.g. atorvastatin, simvastatin) $[13,26]$.

With strong and long traditional use, garlic is often taken by patients in hope for quicker recovery. In common folklore, blogs and healthcare websites, garlic has a reputation to help with recovery from common cold to cancer $[25,26]$; this is at least in part supported by evidence. Though garlic is considered food, high dosage is commonly not recommended for older adults as there is a strong evidence for inhibiting effect on platelets [27]. Those that have slow blood clot formation or patients on anticoagulant therapy should take care when taking garlic. Garlic is not an isolated case; the extensive list of food items that interact with warfarin grows. In a systematic review by Holbrook et al. (2005), several other herbal and natural products and foods were shown to interact with warfarin [28].

\subsubsection{Herbal Products}

Herbal products as ginkgo, St John's wort, ginseng and valerian are among the more commonly reported herbal supplements. These problems may seem more obvious when discussing herbal products, but they may be used instead of or in addition to conventional medication. In addition to influencing patients' diets, these can have interaction with drugs. Ginseng is another well-documented example of an herb with long history of traditional use. The main actions are described as 'adaptogenic' - an action that can be both CNS depressant and stimulant as well as balance bodily functions. These may be conflicting reports, but results of studies of isolated compounds support traditional uses [29]. Preparations are normally well tolerated but its caution is advised. Example of drug interactions is adverse effect with anticoagulants [30] and antiplatelet and anticoagulant effects [31]. Another example is 
the St John's wort with interesting antidepressant effect. Hyperforin has an effect on the liver and the small intestine, through CYP1A2, CYP2C9, CYP2C19, CYP3A, CYP2E1 and P-gp [32]. St John's wort can cause a significant decrease in drug plasma concentration, such as phenprocoumon (anticoagulant). Other drugs affected by hyperforin intake include simvastatin, nifedipine, digoxin, verapamil, dabigatran, rivaroxaban, apixaban and edoxaban [32-34]. What makes herbal products challenging is that the chemical composition varies between producers and it is difficult to predict their potency. Analytical study on different St John's wort products in the USA showed that the concentration of hyperforin ranged from 0.01 to $1.89 \%$, where many contained lower amount than suggested for antidepressant effect [35].

\subsection{Effects of Drugs on Nutrition Status}

\subsubsection{Drugs Likely to Negatively Influence Nutritional Intake/Status}

Medical drugs can negatively impact the bioavailability of nutrients and nutrition status in general [36]. Consequently, the regular use of certain medications has the potential to worsen nutritional status, and this effect of medication on overall nutrition status tends to be multifaceted $[2,3,36]$.

Medication that has the greatest potential to impact nutrition status is usually taken over longer periods of time [36], and according to the Icelandic medical directorate, the most commonly prescribed medications for older adults are beta-blocking agents, drugs for peptic ulcer and gastro-oesophageal reflux disease, hypnotics and sedatives, opioids, beta-lactam antibacterials and penicillins, antidepressants, lipid-modifying agents, antithrombotic agents, anti-inflammatory and antirheumatic products as well as selective calcium channel blockers [37].

Unwanted effects of drugs on nutritional status are a consequence of the drug's pharmacodynamics and by its side effect characteristics [38], and older adults both in community and in a clinical environment are at higher risk due to frequently observed polypharmacy [39].

Frequently, medication negatively affects dietary intake by direct action on digestion as well as on general metabolism [7], consequently affecting an older adult's nutritional status by decreasing dietary intake and bioavailability of essential nutrients, e.g. vitamins, trace elements and electrolytes $[1,2,36]$.

With the aim to maximise drugs' absorption, many drugs have detailed instructions regarding dietary intake (e.g. several antibiotics, antifungal medication [36]) with the consequence of altering the usual routine of eating and meal frequency which can decrease overall energy and nutrients' intake as often observed in older populations $[40,41]$.

Anorexia is a frequently observed side effect of drug therapy leading to a reduction of body weight, and older adults with pre-existing poor nutrition status have to be tightly followed when starting drug therapy with medicines related to hypogeusia and dysgeusia (e.g. metformin, levodopa, lithium) (Chaps. 3, 4 and 5) [36, 40, 41]. 
By direct action of the digestive tract, medications frequently disturb nutrition status of older adults $[36,41]$. Some frequently used medicines lead to xerostomia (e.g. anticholinergic drugs, antidepressants and antipsychotic drugs, diuretics, antihypertensives, sedatives, analgesics, antihistamines), nausea and vomiting (antibiotics, opiates, levodopa, selective serotonin reuptake inhibitors), taste abnormalities (e.g. amphetamines, ampicillin, aspirin, corticosteroids, diltiazem, levodopa, metformin, tricyclic antidepressants, venlafaxine) as well as olfactory disturbances (e.g. ACE inhibitors, amoxicillin, beta-blockers, calcium channel blockers, corticosteroids, levodopa, statins, streptomycin, sumatriptan), decreased gastrointestinal motility (tricyclic antidepressants, opiates) and diarrhoea (e.g. broad-spectrum antibiotics, proton-pump inhibitors, antivirals and antiretrovirals, magnesium salts, iron, lithium, metformin). Even unpleasant smell of medication can reduce food intake [40].

Further, drugs have also the potential to negatively affect the absorption of vitamins or trace elements due to alterations in gastric acidity, diminishing nutrition assimilation, negatively impacting gut microbiota and leading to inflammation of the mucosa of the digestive tract (e.g. antacids, antibiotics, laxatives, anti-inflammatories, hypoglycaemic drugs, lipid-lowering drugs, antidepressants, diuretics).

When negative action of drug therapy on nutrition status is likely to become clinically significant, the nutritional deficiency can be corrected with the use of dietary supplements (e.g. pyridoxine administered with isoniazid, an antibiotic used for the treatment of tuberculosis). Despite the fact that classic symptoms of nutrient deficiency syndromes are not often seen, nutrient insufficiencies can be still related to clinical manifestations. In several cases, the negative impact of a certain medication on nutrition status is acknowledged as adverse drug effects. For example, druginduced osteomalacia is a result of some antiepileptic drugs negatively affecting vitamin D metabolism [42-44]. Further, drug-induced hepatotoxicity and hyperammonaemia (e.g. valproic acid, a drug to treat certain types of seizures) are thought to be a consequence of a lack of carnitine $[45,46]$.

It is still unclear for what drug nutrient interaction dietary supplementation is a feasible solution [47, 48], and this is a field which needs more research in order to be able to recommend prophylactic nutrient supplementation. It should also be mentioned here that there are some drugs that are related to improvements in nutrient status $[49,50]$.

Older adults are likely to use medication that can impair hearing, vision, memory and mobility, resulting into a lack of compliance or wrong dosing [36]. This indirect drug action can then affect food intake by impairing the ability to buy and prepare food or to eat without assistance) [51-54].

\subsection{Drugs Likely to Increase Body Weight}

For a sense of completeness, it should be briefly mentioned here that drugs can also increase body weight. For example, it is well known that active drug ingredients can change function of an older adult's metabolism. Undesirable metabolic adverse effects are frequently observed for antipsychotic drugs which can lead to weight 
gain, hyperglycaemia and dyslipidaemia $[41,55]$, alterations that have been in particular related to the use of second-generation antipsychotics [55-57]. Other frequently used medications such as beta-blockers and steroids have been also shown to increase body weight $[56,58,59]$.

The observed increase in body weight is not necessarily always due to an increase in body fat. There are several potential mechanisms which can explain medicationrelated weight gain: increased appetite (steroids [59] and antidepressants [58]), fluid retention (pioglitazone [60]), increased fat storage (insulin, stimulating the growth of fat cells [61]), slowed metabolism (beta-blockers [62]) and difficulty exercising (antihistamines can make you sleepy, amitriptyline associated with breathing difficulties).

Although maintenance or even an increase in body weight in older adults can be beneficial, these drug-induced changes in body composition and metabolism are usually not positive as they are not associated with positive changes in muscle mass or physical function [57]. If not carefully considered, this may lead to sarcopaenic obesity and also the under-identification and under-treatment of those who are overweight or obese and are also malnourished (Chaps. 7 and 16) [63].

\subsubsection{Conclusion}

Clinical specialists have to recognize that medical drugs and dietary intake interact with each other and can affect the health of older adults. During the last years, these interactions have received more attention and have been better understood in clinical practice [34]. An acknowledgement and broad understanding of the problem are the most important steps towards optimized older adult care [33]. In order to resolve negative drug actions on nutrition status and vice versa, clinicians have to employ a systematic approach and take the time to listen to the perspectives of the older adult. In circumstances where sufficient information on the interactions are available, adverse interactions can be possibly predicted and issues resolved [33].

Healthcare staff should be trained to detect food-drug interactions in order to give older adults instructions on medication, food and beverages. Appropriate specialists must estimate a patient's clinical presentation in order to recognize whether the nutritional status is deteriorating or associated with a drug-induced complication. A change in dosage or a change in medications within the same therapeutic category or a change in dietary habits has to be considered. Finally, and most importantly, healthcare providers should work together with older adults to deliver food and medicine regimens that are most likely to improve older adult outcomes, experiences and quality of life.

\section{Take-Home Points}

- Herbs, fruits as well as alcohol can alter the efficacy of a given drug intervention with adverse consequences.

- In most cases, relevant food-drug interactions change the bioavailability of a medicine. 
- Milk, grapefruit and cranberry juice and garlic are the most common foods to affect drug metabolism.

- Many common medications can lead to weight loss or gain and adverse changes in the nutrition status of older adults.

\section{References}

1. White R (2010) Drugs and nutrition: how side effects can influence nutritional intake. Proc Nutr Soc 69(4):558-564

2. Lombardi LR, Kreys E, Gerry S, Boullata JI (2010) Nutrition in the age of polypharmacy. In: Bendich A, Deckelbaum RJ (eds) Preventive nutrition: the comprehensive guide for health professionals. Humana Press, Totowa, pp 79-123

3. Ased S, Wells J, Morrow LE, Malesker MA (2018) Clinically significant food-drug interactions. Consult Pharm 33(11):649-657

4. Agbabiaka TB, Wider B, Watson LK, Goodman C (2017) Concurrent use of prescription drugs and herbal medicinal products in older adults: a systematic review. Drugs Aging 34(12):891-905

5. Koziolek M, Alcaro S, Augustijns P, Basit AW, Grimm M, Hens B et al (2019) The mechanisms of pharmacokinetic food-drug interactions - a perspective from the UNGAP group. Eur J Pharm Sci 134:31-59

6. Heuberger R (2012) Polypharmacy and food-drug interactions among older persons: a review. J Nutr Gerontol Geriatr 31(4):325-403

7. Boullata JI, Hudson LM (2012) Drug-nutrient interactions: a broad view with implications for practice. J Acad Nutr Diet 112(4):506-517

8. Raats M, de Groot CPGM, van Asselt D (2017) Food for the aging population, 2nd edn. Woodhead Publishing, Duxford

9. Nakanishi T, Tamai I (2015) Interaction of drug or food with drug transporters in intestine and liver. Curr Drug Metab 16(9):753-764

10. Deng J, Zhu X, Chen Z, Fan CH, Kwan HS, Wong CH et al (2017) A review of food-drug interactions on oral drug absorption. Drugs 77(17):1833-1855

11. Abuhelwa AY, Williams DB, Upton RN, Foster DJ (2017) Food, gastrointestinal pH, and models of oral drug absorption. Eur J Pharm Biopharm 112:234-248

12. Ulbricht C, Chao W, Costa D, Rusie-Seamon E, Weissner W, Woods J (2008) Clinical evidence of herb-drug interactions: a systematic review by the natural standard research collaboration. Curr Drug Metab 9(10):1063-1120

13. Rodríguez-Fragoso L, Martínez-Arismendi JL, Orozco-Bustos D, Reyes-Esparza J, Torres E, Burchiel SW (2011) Potential risks resulting from fruit/vegetable-drug interactions: effects on drug-metabolizing enzymes and drug transporters. J Food Sci 76(4):R112-R124

14. Thakkar S, Anklam E, Xu A, Ulberth F, Li J, Li B et al (2020) Regulatory landscape of dietary supplements and herbal medicines from a global perspective. Regul Toxicol Pharmacol 114:104647

15. Sood A, Sood R, Brinker FJ, Mann R, Loehrer LL, Wahner-Roedler DL (2008) Potential for interactions between dietary supplements and prescription medications. Am J Med 121(3):207-211

16. Leyden JJ (1985) Absorption of minocycline hydrochloride and tetracycline hydrochloride. Effect of food, milk, and iron. J Am Acad Dermatol 12(2 pt 1):308-312

17. Jung H, Peregrina AA, Rodriguez JM, Moreno-Esparza R (1997) The influence of coffee with milk and tea with milk on the bioavailability of tetracycline. Biopharm Drug Dispos 18(5):459-463

18. Welling PG, Koch PA, Lau CC, Craig WA (1977) Bioavailability of tetracycline and doxycycline in fasted and nonfasted subjects. Antimicrob Agents Chemother 11(3):462-469 
19. Meyer FP, Specht H, Quednow B, Walther H (1989) Influence of milk on the bioavailability of doxycycline--new aspects. Infection 17(4):245-246

20. Bailey DG, Dresser G, Arnold JM (2013) Grapefruit-medication interactions: forbidden fruit or avoidable consequences? CMAJ 185(4):309-316

21. Oliveira-Freitas VL, Dalla Costa T, Manfro RC, Cruz LB, Schwartsmann G (2010) Influence of purple grape juice in cyclosporine bioavailability. J Ren Nutr 20(5):309-313

22. de Morais C, Oliveira B, Afonso C, Lumbers M, Raats M, de Almeida MD (2013) Nutritional risk of European elderly. Eur J Clin Nutr 67(11):1215-1219

23. Griffiths AP, Beddall A, Pegler S (2008) Fatal haemopericardium and gastrointestinal haemorrhage due to possible interaction of cranberry juice with warfarin. J R Soc Promot Heal 128(6):324-326

24. Ansary J, Forbes-Hernández TY, Gil E, Cianciosi D, Zhang J, Elexpuru-Zabaleta M et al (2020) Potential health benefit of garlic based on human intervention studies: a brief overview. Antioxidants 9(7):619

25. Choo S, Chin VK, Wong EH, Madhavan P, Tay ST, Yong PVC et al (2020) Review: antimicrobial properties of allicin used alone or in combination with other medications. Folia Microbiol (Praha) 65(3):451-465

26. Blalock SJ, Gregory PJ, Patel RA, Norton LL, Callahan LF, Jordan JM (2009) Factors associated with potential medication-herb/natural product interactions in a rural community. Altern Ther Health Med 15(5):26-34

27. Bradley JM, Organ CL, Lefer DJ (2016) Garlic-derived organic polysulfides and myocardial protection. J Nutr 146(2):403s-409s

28. Holbrook AM, Pereira JA, Labiris R, McDonald H, Douketis JD, Crowther M et al (2005) Systematic overview of warfarin and its drug and food interactions. Arch Intern Med 165(10):1095-1106

29. Lim JW, Chee SX, Wong WJ, He QL, Lau TC (2018) Traditional Chinese medicine: herb-drug interactions with aspirin. Singap Med J 59(5):230-239

30. Petersen, MJ, Bergien, SO, Staerk, D (2021) A systematic review of possible interactions for herbal medicines and dietary supplements used concomitantly with diseasemodifying or symptom-alleviating multiple sclerosis drugs. Phytotherapy Research 1-22. https://doi.org/10.1002/ptr.7050

31. Lau AJ, Toh DF, Chua TK, Pang YK, Woo SO, Koh HL (2009) Antiplatelet and anticoagulant effects of Panax notoginseng: comparison of raw and steamed Panax notoginseng with Panax ginseng and Panax quinquefolium. J Ethnopharmacol 125(3):380-386

32. Mouly S, Lloret-Linares C, Sellier PO, Sene D, Bergmann JF (2017) Is the clinical relevance of drug-food and drug-herb interactions limited to grapefruit juice and Saint-John's Wort? Pharmacol Res 118:82-92

33. Borrelli F, Izzo AA (2009) Herb-drug interactions with St John's wort (Hypericum perforatum): an update on clinical observations. AAPS J 11(4):710-727

34. Russo E, Scicchitano F, Whalley BJ, Mazzitello C, Ciriaco M, Esposito S et al (2014) Hypericum perforatum: pharmacokinetic, mechanism of action, tolerability, and clinical drugdrug interactions. Phytother Res 28(5):643-655

35. de los Reyes GC, Koda RT (2002) Determining hyperforin and hypericin content in eight brands of St. John's wort. Am J Health Syst Pharm 59(6):545-547

36. Van Zyl M (2011) The effects of drugs on nutrition. South Afr J Clin Nutr 24(suppl 3): 38-41

37. Directorate IM (2021) Prescription Medicines Register. http://www.landlaeknir.is/tolfraediog-rannsoknir/gagnasofn/gagnasafn/item12455/Lyfjagagnagrunnur-(Prescription-MedicinesRegister). Director of Health [updated 04.05.2017]

38. Gervasio JM (2010) Drug-Induced Changes to Nutritional Status. In: Boullata J, Armenti V (eds) Handbook of Drug-Nutrient Interactions. Nutrition and Health. Humana Press 427-445

39. Knight-Klimas TC, Boullata JI (2004) Drug-nutrient interactions in the elderly. In: Boullata JI, Armenti VT (eds) Handbook of drug-nutrient interactions. Humana Press, Totowa, pp 363-410

40. Pelletier AL, Butler AM, Gillies RA, May JR (2010) Metformin stinks, literally. Ann Intern Med 152(4):267-268 
41. Brixner DI, Said Q, Corey-Lisle PK, Tuomari AV, L'Italien GJ, Stockdale W et al (2006) Naturalistic impact of second-generation antipsychotics on weight gain. Ann Pharmacother 40(4):626-632

42. Pascussi JM, Robert A, Nguyen M, Walrant-Debray O, Garabedian M, Martin P et al (2005) Possible involvement of pregnane $\mathrm{X}$ receptor-enhanced CYP24 expression in drug-induced osteomalacia. J Clin Invest 115(1):177-186

43. Oscarson M, Zanger UM, Rifki OF, Klein K, Eichelbaum M, Meyer UA (2006) Transcriptional profiling of genes induced in the livers of patients treated with carbamazepine. Clin Pharmacol Ther 80(5):440-456

44. Xu Y, Hashizume T, Shuhart MC, Davis CL, Nelson WL, Sakaki T et al (2006) Intestinal and hepatic CYP3A4 catalyze hydroxylation of 1alpha,25-dihydroxyvitamin $\mathrm{D}(3)$ : implications for drug-induced osteomalacia. Mol Pharmacol 69(1):56-65

45. Van Wouwe JP (1995) Carnitine deficiency during valproic acid treatment. Int J Vitam Nutr Res 65(3):211-214

46. Werner T, Treiss I, Kohlmueller D, Mehlem P, Teich M, Longin E et al (2007) Effects of valproate on acylcarnitines in children with epilepsy using ESI-MS/MS. Epilepsia 48(1):72-76

47. Morrow LE, Wear RE, Schuller D, Malesker M (2006) Acute isoniazid toxicity and the need for adequate pyridoxine supplies. Pharmacotherapy 26(10):1529-1532

48. De Vivo DC, Bohan TP, Coulter DL, Dreifuss FE, Greenwood RS, Nordli DR Jr et al (1998) L-carnitine supplementation in childhood epilepsy: current perspectives. Epilepsia 39(11):1216-1225

49. Drain PK, Kupka R, Mugusi F, Fawzi WW (2007) Micronutrients in HIV-positive persons receiving highly active antiretroviral therapy. Am J Clin Nutr 85(2):333-345

50. Nose S, Wasa M, Tazuke Y, Owari M, Fukuzawa M (2010) Cisplatin upregulates glutamine transport in human intestinal epithelial cells: the protective mechanism of glutamine on intestinal mucosa after chemotherapy. JPEN J Parenter Enteral Nutr 34(5):530-537

51. Tawara Y, Nishikawa T, Koga I, Uchida Y, Yamawaki S (1997) Transient and intermittent oral dyskinesia appearing in a young woman ten days after neuroleptic treatment. Clin Neuropharmacol 20(2):175-178

52. Halford JC, Blundell JE (2000) Pharmacology of appetite suppression. Prog Drug Res $54: 25-58$

53. Zadak Z, Hyspler R, Ticha A, Vlcek J (2013) Polypharmacy and malnutrition. Curr Opin Clin Nutr Metab Care 16(1):50-55

54. Boullata JI (2013) Drug and nutrition interactions: not just food for thought. J Clin Pharm Ther 38(4):269-271

55. Yoon S, Noh JS, Choi SY, Baik JH (2010) Effects of atypical antipsychotic drugs on body weight and food intake in dopamine D2 receptor knockout mice. Biochem Biophys Res Commun 393(2):235-241

56. Williams SG, Alinejad NA, Williams JA, Cruess DF (2010) Statistically significant increase in weight caused by low-dose quetiapine. Pharmacotherapy 30(10):1011-1015

57. (2004) Consensus development conference on antipsychotic drugs and obesity and diabetes. Diabetes Care 27(2):596-601

58. Alam A, Voronovich Z, Carley JA (2013) A review of therapeutic uses of mirtazapine in psychiatric and medical conditions. Prim Care Companion CNS Disord 15(5):PCC.13r01525

59. Uddén J, Björntorp P, Arner P, Barkeling B, Meurling L, Rössner S (2003) Effects of glucocorticoids on leptin levels and eating behaviour in women. J Intern Med 253(2):225-231

60. Yang T, Soodvilai S (2008) Renal and vascular mechanisms of thiazolidinedione-induced fluid retention. PPAR Res 2008:943614

61. Kahn BB, Flier JS (2000) Obesity and insulin resistance. J Clin Invest 106(4):473-481

62. Wharton S, Raiber L, Serodio KJ, Lee J, Christensen RA (2018) Medications that cause weight gain and alternatives in Canada: a narrative review. Diabetes Metab Syndr Obes 11:427-438

63. Bell JJ, Pulle RC, Lee HB, Ferrier R, Crouch A, Whitehouse SL (2021) Diagnosis of overweight or obese malnutrition spells DOOM for hip fracture patients: a prospective audit. Clin Nutr 40:1905-1910 


\section{Recommended Reading}

Gervasio JM (2010) Drug-induced changes to nutritional status. In: Boullata JI, Armenti V (eds) Handbook of drug-nutrient interactions, 2nd edn. Human Press, Totowa

Heuberger R (2012) Polypharmacy and food-drug interactions among older persons: a review. J Nutr Gerontol Geriatr 31(4):325-403

Open Access This chapter is licensed under the terms of the Creative Commons Attribution 4.0 International License (http://creativecommons.org/licenses/by/4.0/), which permits use, sharing, adaptation, distribution and reproduction in any medium or format, as long as you give appropriate credit to the original author(s) and the source, provide a link to the Creative Commons license and indicate if changes were made.

The images or other third party material in this chapter are included in the chapter's Creative Commons license, unless indicated otherwise in a credit line to the material. If material is not included in the chapter's Creative Commons license and your intended use is not permitted by statutory regulation or exceeds the permitted use, you will need to obtain permission directly from the copyright holder.

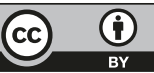

